\title{
Diagnóstico da Gestão de Resíduos Sólidos Urbanos no Brasil: Uma análise pós PNSB 2008 - ênfase na destinação final e nos resíduos orgânicos
}

\author{
Evaluation of Urban Solid Waste in Brazil: an analysis after PNSB 2008 - \\ Focus on final destination and organic waste
}

Luciana Miyoko Massukado | Bruno Milanez
Gustavo Luedemann | Jorge Hargrave

Data de entrada: 25/06/2012 | Data de aprovação: 23/10/2012

Resumo

Este artigo apresenta uma análise do diagnóstico da gestão dos Resíduos Sólidos Urbanos (RSU) no Brasil focando a destinação final e os resíduos orgânicos. A elaboração se deu, principalmente, a partir das informações contidas na Pesquisa Nacional de Saneamento Básico (PNSB) e no Sistema Nacional de Informações sobre Saneamento (SNIS). Os resultados apontam que, em 2008, somente 1,6\% dos resíduos eram encaminhados à compostagem e 60\% dos RSU eram destinados para aterros sanitários. No entanto, $86 \%$ dos municípios realizavam a disposição em lixões e aterros controlados. A partir deste diagnóstico infere-se que é necessário incentivar a implantação de novas unidades de compostagem e os programas devem levar em consideração a separação dos resíduos orgânicos na fonte. Para se alcançar a meta da erradicação dos lixões (Lei 12.305/2010), a formação de consórcios públicos surge como alternativa para os municípios, principalmente para os de pequeno porte.

Palavras-chave: Resíduos sólidos urbanos, compostagem, disposição final.

\section{Abstract}

This paper evaluates the performance of Municipal Solid Waste (MSW) management in Brazil. We focus on composting and on solid waste final disposal. The evaluation is mainly based on the "Pesquisa Nacional de Saneamento Básico" and on the "Sistema Nacional de Informações sobre Saneamento". In 2008, only 1.6\% of organic waste was sent for composting plants and 60\% of MSW were disposed in landfills, but 86\% of municipalities sent their waste to dumps or controlled landfills. For composting, it is important to develop more plants. In order to guarantee composting programs and, projects 'effectiveness, they must take into account the separation of organic waste at source, institutional arrangements, legislation and consumer market. Consortia to dispose waste, mainly for small cities, could be a solution to achieve the goal of dumps eradication.

Key-words: Municipal solid waste, composting, final disposal.

\footnotetext{
Luciana Miyoko Massukado*

Engenheira civil (UFSCar). Doutora em Ciências da Engenharia Ambiental (EESC/USP). Docente do Instituto Federal de Educação, Ciência e Tecnologia de Brasília - Campus Planaltina. luciana.massukado@ifb.edu.br

Bruno Milanez

Engenheiro de Produção (UFRJ) e Doutor em Política Ambiental (Lincoln University). Professor adjunto do Departamento de Engenharia de Produção e Mecânica da Universidade Federal de Juiz de Fora. bruno.milanez@ufjf.edu.br

Gustavo Luedemann

Bacharel em ciências biológicas (UNB). Mestre em ecologia (UNB) e doutorando em ecologia pela TU München, Alemanha. Coordenador de estudos em sustentabilidade ambiental do IPEA. gustavo.luedemann@ipea.gov.br

Jorge Hargrave

Economista (UNICAMP). Mestre em Economia pela University of Freiburg /Alemanha. Técnico de Planejamento e Pesquisa do Instituto de Pesquisa Econômica Aplicada (IPEA) - jorge.hargrave@ipea.gov.br

* Endereço para correspondência: Instituto Federal de Educação, Ciência e Tecnologia de Brasília - Campus Planaltina Rodovia DF-128, Km 21, Zona Rural de Planaltina, Planaltina/DF - CEP 73380-900
} 


\section{Introdução}

Este artigo apresenta um diagnóstico da gestão de Resíduos Sólidos Urbanos (RSU), discutindo os principais desafios que se colocam para o aprimoramento dessa gestão no país. A pesquisa original que deu origem a este artigo foi realizada dentro do projeto "Diagnóstico da situação atual dos resíduos sólidos no Brasil - apoio técnico para a elaboração da proposta preliminar do Plano Nacional de Resíduos Sólidos" (Chamada Pública Simplificada IPEA/PNPD Nº 016/2011).

No que diz respeito ao tratamento de resíduos, apesar da massa de resíduos sólidos apresentar elevado percentual de resíduos orgânicos, observa-se que as experiências de compostagem no Brasil são ainda incipientes. O resíduo orgânico, por não ser coletado separadamente, acaba sendo encaminhado para disposição final juntamente com os resíduos perigosos e com os secos que deixaram de ser coletados seletivamente (Massukado, 2008). Quanto à disposição final dos resíduos algumas cidades brasileiras a fazem em lixões a céu aberto ou em aterros controlados que por não serem formas adequadas de disposição, acarretam problemas ambientais e de saúde pública.

Neste artigo são adotadas as definições da Lei 12.305/2010 que instituiu a Política Nacional de Resíduos Sólidos. De acordo com essa Lei, a destinação final ambientalmente adequada é definida como "a destinação de resíduos que inclui a reutilização, a reciclagem, a compostagem, a recuperação e o aproveitamento energético ou outras destinações admitidas pelos órgãos competentes do SISNAMA, do SNVS e do Suasa ${ }^{1}$, entre elas a disposição final, observando normas operacionais específicas de modo a evitar danos ou riscos à saúde pública e à segurança e a minimizar os impactos ambientais adversos" (Brasil, 2010).

A Lei também diferencia resíduo sólido e rejeito, sendo o primeiro definido como "material, substância, objeto ou bem descartado resultante de atividades humanas em sociedade, a cuja destinação final se procede, se propõe proceder ou se está obrigado a proceder, nos estados sólido ou semissólido, bem como gases contidos em recipientes e líquidos cujas particularidades tornem inviável o seu lançamento na rede pública de esgotos ou em corpos d'água, ou exijam para isso soluções técnica ou economicamente invi- áveis em face da melhor tecnologia disponível". Os rejeitos são aqueles "resíduos sólidos que, depois de esgotadas todas as possibilidades de tratamento e recuperação por processos tecnológicos disponíveis e economicamente viáveis, não apresentem outra possibilidade que não a disposição final ambientalmente adequada”. Considerando essas definições tem-se que somente o que for rejeito deve ir para a disposição final ambientalmente adequada e os demais resíduos devem ser encaminhados para outras formas de destinação final (reciclagem, compostagem, incineração, etc).

\section{Metodologia}

O trabalho foi elaborado a partir das informações contidas na Pesquisa Nacional de Saneamento Básico (PNSB), utilizando o Banco Multidimensional Estatístico (BME), e no Sistema Nacional de Informação em Saneamento (SNIS). Cabe destacar que o universo pesquisado em cada uma dessas pesquisas é diferente e a metodologia de cada uma parte de objetivos distintos, gerando ao final, informações por vezes desencontradas.

O presente diagnóstico de RSU é analisado sob três universos - o primeiro considera o país como unidade de análise; o segundo trabalha com as cinco regiões brasileiras e o último considera o porte do município, definido em função da população. Nesse caso, foram considerados como municípios de pequeno porte aqueles que possuíam população total menor que 100 mil habitantes; municípios de médio porte aqueles com mais de 100 mil e menos que 1 milhão de habitantes, e por fim, municípios de grande porte aqueles com população acima de 1 milhão de habitantes.

Com relação à destinação final é importante destacar que no estudo da quantidade de resíduos destinados foi necessário adequar os valores apresentados na Pesquisa Nacional de Saneamento Básico (2000 e 2008). Isso se deve ao fato de que a quantidade total coletada não coincidia com a quantidade total destinada. A hipótese mais plausível encontrada foi a de que poderia haver duplicidade nos valores informados pelos municípios e entidades prestadoras de serviço em relação à quantidade de resíduos destinada ao próprio município e aquela destinada para outro município.

1- SISNAMA: Sistema Nacional de Meio Ambiente; SNVS: Sistema Nacional de Vigilância Sanitária e Suasa: Sistema Único de Atenção à Sanidade Agropecuária. 


\section{Resultados e discussões}

\section{Destinação final}

Considerou-se neste trabalho somente a quantidade de resíduos e rejeitos encaminhados para destino final no próprio município. Na Tabela 1 é apresentada a quantidade diária de RSU encaminhados para a destinação final.

Em uma análise geral, a quantidade de resíduos encaminhados para destinação final aumentou, em média, 35\% em um intervalo de oito anos. Com relação à distribuição por região, todas apresentaram aumento na quantidade total encaminhada para algum tipo de destino final. Quanto à distribuição por estrato populacional somente os municípios de grande porte apresentaram redução significativa do total de resíduos encaminhados para um destino final ${ }^{2}$.

Tanto na PNSB 2000 quanto na PNSB 2008 observa-se que, mais de $90 \%$, em massa, dos resíduos são destinados para a disposição final em aterros sanitários, aterros controlados e lixões, sendo os 10\% restantes distribuídos entre unidades de compostagem, unidades de triagem e reciclagem, unidades de incineração, vazadouros em áreas alagadas e outros destinos, como mostra a Tabela 2.

\begin{tabular}{l|c|c|c|c}
\multirow{2}{*}{ Unidade de análise } & \multicolumn{2}{|c|}{$\begin{array}{c}\text { Quantidade de resíduos encaminhados para } \\
\text { destinação final (t/dia) }\end{array}$} & $\begin{array}{c}\text { Quantidade de resíduos destinados por } \\
\text { habitante urbano (kg/hab.dia) }\end{array}$ \\
\cline { 2 - 5 } & 2000 & 2008 & 2000 & 2008 \\
\hline Brasil & 140.080 & 188.815 & 1,0 & 1,2 \\
\hline Municípios pequenos & 53.035 & 81.209 & 1,0 & 1,3 \\
\hline Municípios médios & 46.249 & 79.306 & 0,9 & 1,4 \\
\hline Municípios grandes & 40.796 & 28.300 & 1,2 & 0,7 \\
\hline Norte & 10.929 & 14.229 & 1,2 & 1,3 \\
\hline Nordeste & 33.876 & 55.723 & 1,0 & 1,4 \\
\hline Sudeste & 67.656 & 84.227 & 1,0 & 1,1 \\
\hline Sul & 16.893 & 21.929 & 0,8 & 0,9 \\
\hline Centro-Oeste & 10.725 & 12.706 & 1,1 & 1,0
\end{tabular}

Fonte: Elaborado a partir de IBGE (2002, 2010)

Tabela 1- Quantidade diária de RSU encaminhados para destinação final, em 2000 e 2008

\begin{tabular}{l|c|c|c|c}
\multirow{2}{*}{ Destino Final } & \multicolumn{2}{c|}{2000} & \multicolumn{2}{c}{2008} \\
\cline { 2 - 5 } & Quantidade (t/dia) & $\%$ & Quantidade (t/dia) & $\%$ \\
\hline Aterro sanitário & 49.615 & 35,4 & 110.044 & 58,3 \\
\hline Aterro controlado & 33.854 & 24,2 & 36.673 & 19,4 \\
\hline Vazadouros a céu aberto (Lixão) & 45.485 & 32,5 & 37.361 & 19,8 \\
\hline Unidade de compostagem & 6.364 & 4,5 & 1.519 & 0,8 \\
\hline Unidade de triagem para reciclagem & 2.158 & 1,5 & 2.592 & 1,4 \\
\hline Unidade de incineração & 483 & 0,3 & 65 & $<0,1$ \\
\hline Vazadouro em áreas alagáveis & 228 & 0,2 & 35 & $<0,1$ \\
\hline Locais não fixos & 877 & 0,6 & $\mathrm{~N} / \mathrm{D}$ & \\
\hline Outra unidade & 1.015 & 0,7 & 525 & 0,3 \\
\hline Total & 140.080 & & 188.815 &
\end{tabular}

Fonte: Elaborado a partir de IBGE (2002, 2010) / N/D: não disponível. Na PNSB 2008 não se utilizou essa opção como destino final

Tabela 2- Quantidade diária de RSU encaminhados para diferentes formas de destinação final, para os anos 2000 e 2008

2- A hipótese é de que nos grandes municípios ocorreu o encerramento de alguns aterros sanitários e a não implantação de novos no próprio município, sendo os resíduos encaminhados para aterros sanitários de outros municípios. 
Na Tabela 3 é apresentada a quantidade de municípios de acordo com o tipo de disposição final para os RSU.

Analisando a Tabela 3 observa-se que, nesse intervalo de tempo, praticamente dobrou o número de municípios que destinavam seus resíduos em aterro sanitário, apesar da disposição final em lixões ainda ser realidade em 50\% dos municípios brasileiros.

\section{Compostagem}

A Lei 12.305/2010 em seu Art $3^{\circ}$, inciso VII considera a compostagem como uma forma de destinação final ambientalmente adequada de resíduos (Brasil, 2010). A Tabela 4 apresenta a situação das unidades de compostagem nos anos 2000 e 2008.

Observa-se que, apesar do aumento do número de municípios com unidades de compostagem, a

\begin{tabular}{l|c|c|c|c}
\multirow{2}{*}{\multicolumn{1}{c|}{ Destino Final }} & \multicolumn{2}{c|}{ Número de municípios } & \multicolumn{2}{c}{ Percentual de municípios* } \\
\cline { 2 - 5 } & 2000 & 2008 & 2000 & 2008 \\
\hline Aterro sanitário & 810 & 1.540 & 14,5 & 27,7 \\
\hline Aterro Controlado & 1.074 & 1.254 & 19,3 & 22,5 \\
\hline Vazadouros a céu aberto (Lixão) & 3.763 & 2.810 & 54,61 & 50,5 \\
\hline Unidade de compostagem & 157 & 211 & 2,8 & 3,8 \\
\hline Unidade de triagem para reciclagem & 248 & 643 & 4,5 & 11,6 \\
\hline Unidade de incineração & 176 & 134 & 3,2 & 0,6 \\
\hline Vazadouro em áreas alagáveis & 33 & 14 & 0,6 & 0,3 \\
\hline Locais não fixos & 109 & N/D & 2 & N/D \\
\hline Outra unidade & 43 & 134 & 0,8 & 2,4 \\
\hline Total de municípios & 5.565 & 5.565 & & \\
\hline
\end{tabular}

Fonte: Elaborado a partir de IBGE (2002, 2010)

* A soma das porcentagens é maior que $100 \%$, pois um mesmo município pode ter mais de uma forma de destinação final para seus resíduos.

Tabela 3- Destinação final de RSU por número de municípios, em 2000 e 2008

\begin{tabular}{l|c|c|c|c}
\multicolumn{1}{|c|}{ Unidade de análise } & \multicolumn{2}{c}{$\begin{array}{c}\text { Número de municípios com uni- } \\
\text { dades de compostagem no pró- } \\
\text { prio município }\end{array}$} & $\begin{array}{c}\text { Quantidade de resíduos encaminhados } \\
\text { para unidades de compostagem no } \\
\text { próprio município (t/dia) }\end{array}$ \\
\hline Brasil & 2000 & 2008 & 2000 & 2008 \\
\hline Municípios pequenos & 157 & 211 & $6.364,5$ & $1.519,5$ \\
\hline Municípios médios & 139 & 190 & 529,8 & 497,2 \\
\hline Municípios grandes & 15 & 12 & 751,0 & 495,0 \\
\hline Norte & 3 & 6 & $5.083,3$ & 527,7 \\
\hline Nordeste & 1 & 3 & 5,0 & 18,4 \\
\hline Sudeste & 17 & 3 & 112,5 & 13,0 \\
\hline Sul & 70 & 110 & $5.368,9$ & 684,6 \\
\hline Centro-Oeste & 68 & 92 & 192,5 & 475,3 \\
\hline
\end{tabular}

Fonte: Elaborado a partir de IBGE (2002, 2010)

Tabela 4- Número de municípios com unidades de compostagem e quantidade total de resíduos encaminhados para esses locais 
quantidade tratada foi reduzida. Essa redução foi mais expressiva na região sudeste que em 2000 tratava 5.368,9 t/dia de resíduos orgânicos e em 2008 passou a tratar $684,6 \mathrm{t} / \mathrm{dia}^{3}$. A avaliação do potencial existente para tratamento da fração orgânica dos resíduos sólidos produzidos foi feita a partir da composição gravimétrica dos resíduos coletados no Brasil. Para tanto, foi construída a Tabela 5 a partir da média simples da composição gravimétrica de 93 municípios brasileiros, pesquisados entre 1995 e 2008 e compilados por IPEA (2012).

A Tabela 6 apresenta para o ano de 2008, a porcentagem de matéria orgânica tratada em relação ao total estimado coletado utilizando, como referência a composição gravimétrica média encontrada para o Brasil.

No geral, tem-se que de um total estimado de matéria orgânica coletada de 94.309,5 t/dia apenas 1,6\% dos resíduos orgânicos são destinados para unidades de compostagem, sendo o restante encaminhado para outros destinos finais, desta-

\begin{tabular}{|c|c|c|c|}
\hline \multirow{2}{*}{ Materiais } & \multirow{2}{*}{ Participação (\%) } & \multicolumn{2}{|c|}{ Quantidade (t/dia) } \\
\hline & & 2000 & 2008 \\
\hline Material reciclável & 31,9 & $47.558,5$ & $58.527,4$ \\
\hline Metais & 2,9 & $4.301,5$ & $5.293,5$ \\
\hline Aço & 2,3 & $3.424,0$ & $4.213,7$ \\
\hline Alumínio & 0,6 & 877,5 & $1.079,9$ \\
\hline Papel, papelão e tetrapak & 13,1 & $19.499,9$ & $23.997,4$ \\
\hline Plástico total & 13,5 & $20.191,1$ & $24.847,9$ \\
\hline Plástico filme & 8,9 & $13.326,1$ & $16.399,6$ \\
\hline Plástico rígido & 4,6 & $6.865,0$ & $8.448,3$ \\
\hline Vidro & 2,4 & $3.566,1$ & $4.388,6$ \\
\hline Matéria orgânica & 51,4 & $76.655,3$ & $94.335,1$ \\
\hline Outros & 16,7 & $24.880,5$ & $30.618,9$ \\
\hline Total & 100,0 & $149.094,3$ & $183.481,5$ \\
\hline
\end{tabular}

Fonte: Elaborado a partir de IBGE (2010) e IPEA (2012)

Tabela 5- Estimativa da composição gravimétrica dos resíduos sólidos coletados no Brasil

3- Essa redução pode ser atribuída ao município de São Paulo que, em 2000, encaminhava 4.290 t/dia para a compostagem e, em 2008, não enviava mais resíduos para unidades de compostagem. O fechamento das usinas de compostagem Vila Leopoldina, em 2004, e São Mateus em 2003 (SMA 2004 ; ARAUJO, 2005; BARREIRA, 2008) e a não instalação de uma nova refletiu na redução da quantidade de resíduos encaminhada para a unidade de compostagem. 


\begin{tabular}{l|c|c|c|}
\hline \multicolumn{1}{|c|}{ Unidade de análise } & $\begin{array}{c}\text { Quantidade enviada } \\
\text { para compostagem } \\
\text { (t/dia) }\end{array}$ & $\begin{array}{c}\text { Estimativa da quantidade } \\
\text { de matéria orgânica coleta- } \\
\text { da* (t/dia) }\end{array}$ & $\begin{array}{c}\text { Taxa de tratamento em } \\
\text { função da quantidade } \\
\text { coletada (\%) }\end{array}$ \\
\hline Municípios pequenos & $\mathbf{1 . 5 1 9 , 5}$ & $\mathbf{9 4 . 3 0 9 , 1}$ & 1,6 \\
\hline Municípios médios & 497,2 & $40.797,3$ & 1,5 \\
\hline Municípios grandes & 495,0 & $32.250,1$ & 0,2 \\
\hline Norte & 527,7 & $7.523,5$ & $<0,1$ \\
\hline Nordeste & 18,4 & $24.262,6$ & 1,9 \\
\hline Sudeste & 13,0 & $35.044,1$ & 2,5 \\
\hline Sul & 684,6 & $19.193,7$ & 3,9 \\
\hline Centro-Oeste & 475,3 & $8.285,2$ & 2 \\
\hline
\end{tabular}

Fonte: Elaborado a partir de IBGE (2010) e Tabela 5

* Quantidade estimada equivale a quantidade total coletada multiplicando-se pela porcentagem da composição gravimétrica.

Tabela 6- Matéria orgânica tratada em relação ao total estimado coletado, em 2008

cando-se os lixões, aterros controlados e aterros sanitários. Considerando os Estados, observa-se que somente 14 possuem unidades de compostagem, com destaque para Rio Grande do Sul, Rio de Janeiro e Minas Gerais.

A partir desses levantamentos, verifica-se que a compostagem é ainda pouco utilizada em programas municipais de gerenciamento dos RSU. Os motivos vão desde a dificuldade de se obter os resíduos orgânicos já separados na fonte geradora; a insuficiência de manutenção do processo; ao preconceito com o produto; a carência de investimentos; passando pela falta de tecnologia adequada para a coleta deste tipo de material até as exigências de licenciamento ambiental, que não diferenciam o porte da instalação, dificultando as iniciativas de pequeno porte (Massukado, 2008).

Complementando o relato, é importante também analisar os interesses distintos dos atores envolvidos nos programas de compostagem que, segundo Ali (2004), podem ser assim resumidos:

- O governo e administrações locais buscam alternativas que desviem a maior quantidade possível de resíduos dos aterros sanitários;
- As universidades e centros de pesquisa preocupam-se na proposição de novos modelos de gestão, no desenvolvimento ou melhoramento de tecnologias e também na avaliação da qualidade do composto produzido;

- As organizações não-governamentais buscam divulgar boas práticas de gestão de resíduos sólidos e criar oportunidades de emprego;

- As empresas privadas ficam atentas às oportunidades de mercados e ao lançamento de novas tecnologias e produtos no intuito de aumentar seus ganhos; e

- As agências ou secretarias de meio ambiente ficam responsáveis pelo estabelecimento de normas e leis, visando sempre à conservação do meio ambiente.

O mesmo autor aponta para a perda de foco como um dos problemas dos projetos de compostagem nos países em desenvolvimento. Isso significa dizer que a maioria dos projetos tem muitas metas (solucionar o problema da quantidade crescente de resíduos que é encaminhado ao aterro, geração de emprego e renda, transformar o adubo em fertilizante para o solo), dificultando a sua continuidade. 
Com relação aos objetivos estratégicos para a implantação de unidades de compostagem, o relatório do MMA (2010) vai ao encontro com o pensamento de Ali (2004) ao enfatizar que os "objetivos a serem alcançados precisam ser definidos antes de se iniciar o planejamento operacional, pois podem indicar escolhas diferentes quanto aos métodos a serem empregados".

\section{Disposição final}

\section{Dados quantitativos}

A Lei 12.305/2010 considera, em seu Art $3^{\circ}$, a disposição final ambientalmente adequada como a distribuição ordenada de rejeitos em aterros, observando normas operacionais específicas de modo a evitar danos ou riscos à saúde pública, à segurança e a minimizar os impactos ambientais adversos (Brasil, 2010).

Todavia, no Brasil, não se pode dizer que os aterros sanitários - locais de disposição ambientalmente adequados - recebem somente rejeitos. Na realidade, o que ocorre ainda é a disposição final dos resíduos em solo, sendo as principais formas os lixões, aterros controlados e aterros sanitários, que receberam 90\% da quantidade total dos resíduos encaminhados para destino final no próprio município, conforme Tabela 7 .

A partir desses dados, observa-se que, em termos quantitativos, houve um aumento de 120\% na quantidade RSU dispostos em aterros sanitários e uma redução de $18 \%$ na quantidade de resíduos e rejeitos encaminhada para lixões entre 2000 e 2008.

De acordo com a Tabela 7 , os municípios de pequeno e médio porte tiveram acréscimos significativos, respectivamente, $370 \%$ e $165 \%$, na quantidade de resíduos encaminhada para disposição em aterros sanitários. O fato de os municípios de grande porte não terem aumentado tanto a quantidade de resíduos dispostos no aterro pode ter ocorrido em função da escassez de locais adequados para disposição dos resíduos nesses locais. As regiões Sul e Sudeste apresentaram redução de aproximadamente $70 \%$ na quantidade de resíduos enviados para os lixões. Todas as regiões tiveram acréscimo na quantidade de resíduos encaminhada para aterros sanitários, com destaque especial, para as regiões norte e nordeste.

Apesar de a quantidade de RSU destinados para

\begin{tabular}{l|c|c|c|c|c|c} 
& \multicolumn{2}{|c|}{ Lixão } & \multicolumn{2}{c}{ Aterro Controlado } & \multicolumn{2}{c}{ Aterro sanitário } \\
\cline { 2 - 7 } & 2000 & 2008 & 2000 & 2008 & 2000 & 2008 \\
\hline Brasil & 45.485 & 37.361 & 33.854 & 36.673 & 49.614 & 110.044 \\
\hline Municípios pequenos & 34.533 & 32.504 & 10.406 & 14.068 & 6.878 & 32.421 \\
\hline Municípios médios & 10.220 & 4.845 & 15.525 & 17.278 & 17.106 & 45.203 \\
\hline Municípios grandes & 832 & 12 & 7.923 & 5.327 & 25.630 & 32.420 \\
\hline Norte & 6.148 & 4.892 & 3.222 & 4.688 & 1.350 & 4.540 \\
\hline Nordeste & 20.580 & 23.462 & 6.113 & 6.819 & 6.715 & 25.2467 \\
\hline Sudeste & 11.521 & 3.636 & 15.685 & 16.767 & 32.568 & 61.577 \\
\hline Sul & 4.646 & 1.433 & 4.699 & 3.485 & 5.882 & 15.293 \\
\hline Centro-Oeste & 2.5890 & 3.938 & 4.135 & 4.914 & 3.099 & 3.387
\end{tabular}

Fonte: Elaborado a partir de IBGE (2002, 2010)

Tabela 7- Disposição final dos RSU e rejeitos no Brasil, em t/dia, considerando lixão, aterro controlado e aterro sanitário 
aterros sanitários terem aumentado significativamente entre 2000 e 2008, ainda há 74.034 t/ dia de resíduos com disposição inadequada, seja em lixões ou aterros controlados. Em relação às macrorregiões, as regiões Sul e Sudeste têm melhor desempenho com relação à quantidade de resíduos dispostas adequadamente. As regiões Norte, Nordeste e Centro Oeste ainda dispõem mais da metade dos resíduos de forma inadequada. A Tabela 8 resume o número existente de unidades para disposição final dos rejeitos e RSU.

Conforme pode ser visto na Tabela 8 , houve um aumento do número de unidades de disposição no solo em aterros sanitários, ao mesmo tempo em que se reduz o número de lixões e aterros controlados. Tanto os municípios de pequeno e médio, quanto os de grande porte reduziram o número de lixões, ao mesmo tempo em que a quantidade de novos aterros sanitários praticamente dobrou nos municípios de pequeno porte.

Com relação à quantidade de rejeitos e resíduos encaminhados para algum tipo de disposição final, tem-se que, em 2000, 35\% dos RSU eram dispostos em lixões, 26\% em aterros controlados e 39\% em aterros sanitários. Em 2008, o cenário mudou, sendo que $20 \%$ dos RSU eram dispostos em lixões, 20\% em aterros controlados e 60\% em aterros sanitários. Quando a análise é realizada sob a ótica das unidades de disposição final tem-se que, em 2000, 68\% das unidades de disposição no solo correspondiam aos lixões, 18\% aterros controlados e $14 \%$ aterros sanitários. Por outro lado, em 2008, 49\% das unidades de disposição no solo eram lixões, $22 \%$ aterro controlados e $29 \%$ aterros sanitários. Ou seja, em ambas as métricas, a participação dos aterros sanitários subiu e dos lixões caiu entre 2000 e 2008.

Além das informações obtidas na base do Banco Multidimensional de Estatística do IBGE para analisar os dados de disposição final dos resíduos no Brasil foi consultado o documento Projeto do Plano Nacional de Saneamento Básico no qual constam as metas de curto, médio e longo prazo para os sistemas de saneamento - abastecimento de água, esgotamento sanitário, manejo de resíduos sólidos e drenagem de águas pluviais (MCidades, 2011).

Especificamente para o manejo dos resíduos sólidos destaca-se a meta R3 - número de municípios com presença de lixão/vazadouro de resíduos sólidos/total de município. Esse documento propõe como indicador para essa meta a "\% de

\begin{tabular}{l|c|c|c|c|c|c}
\multirow{2}{*}{ Unidade de análise } & \multicolumn{2}{|c|}{ Lixão } & \multicolumn{2}{c}{ Aterro Controlado } & \multicolumn{2}{c}{ Aterro sanitário } \\
\cline { 2 - 7 } & 2000 & 2008 & 2000 & 2008 & 2000 & 2008 \\
\hline Brasil & 4.642 & 2.906 & 1.231 & 1.310 & 931 & 1.723 \\
\hline Municípios pequenos & 4507 & 2.863 & 1096 & 1.226 & 773 & 1.483 \\
\hline Municípios médios & 133 & 42 & 130 & 78 & 125 & 207 \\
\hline Municípios grandes & 2 & 1 & 5 & 6 & 33 & 43 \\
\hline Norte & 430 & 388 & 44 & 45 & 19 & 157 \\
\hline Nordeste & 2273 & 1655 & 142 & 116 & 77 & 645 \\
\hline Sudeste & 1040 & 317 & 475 & 807 & 463 & 805 \\
\hline Sul & 584 & 197 & 466 & 256 & 280 & 71 \\
\hline Centro-Oeste & 315 & 349 & 104 & 86 & 92 & 75 \\
\hline
\end{tabular}

Nota: Um mesmo município pode apresentar mais de um tipo de destinação de resíduos / Fonte: Elaborado a partir de IBGE (2002, 2010)

Tabela 8- Número de unidades para disposição final dos rejeitos e RSU 


\begin{tabular}{c|c|c|c|c|c}
\multirow{2}{*}{ Unidade de Análise } & \multirow{2}{*}{ No municípios } & \multicolumn{2}{|c|}{ Lixões } & \multicolumn{2}{c}{ Municípios com presença de lixões } \\
\cline { 3 - 6 } & & Quantidade & $\%$ & Quantidade & 50,5 \\
\hline Brasil & 5.565 & 2.906 & 52,2 & 2.810 & 84,6 \\
\hline Norte & 449 & 388 & 86,4 & 380 & 89,1 \\
\hline Nordeste & 1.794 & 1.655 & 92,3 & 1.598 & 18,4 \\
\hline Sudeste & 1.668 & 317 & 19,0 & 311 & 15,3 \\
\hline Sul & 1.188 & 197 & 16,6 & 182 & 72,7 \\
\hline
\end{tabular}

Fonte: Elaborado a partir de IBGE (2010)

Tabela 9- Número lixões e de municípios com presença de lixões em 2008

municípios com presença de lixão/vazadouro de resíduos sólidos", no qual foram estabelecidas metas progressivas de expansão e qualidade dos serviços, para as cinco macrorregiões e para o país. Nesse caso em específico, não houve metas progressivas e sim um meta única, ou seja, que a partir de 2015, não exista mais municípios dispondo seus resíduos e rejeitos em lixões ou vazadouros a céu aberto.

A Tabela 9 apresenta o resumo do número de municípios que tinham lixões em 2008, assim como a quantidade total de lixões existentes. Esses dados mostram que no Brasil há um número maior de lixões do que a quantidade de municípios com esse tipo de disposição, significando que em um mesmo município pode haver mais de um lixão. Outra análise é que enquanto nas regiões Sul e Sudeste respectivamente apenas 15,3 e $18,4 \%$ dos municípios têm lixões, nas regiões Norte e Nordeste esses percentuais são 84,6 e $89,1 \%$ respectivamente.

Cabe dar destaque a observação apresentada na proposta do Plano Nacional de Saneamento Básico (MCidades, 2011) o qual afirma que a meta apresentada para o indicador R3 visam cumprir a determinação da Lei ${ }^{\circ} 12.305 / 2010$, que estabelece a erradicação de lixões até 2014 (Brasil, 2010). O referido documento alerta para os resultados obtidos em uma consulta com especialistas, que apontaram metas menos otimistas, obtendo-se valores de 35\%, 23\% e 0\%, respectivamente para 2015, 2020 e 2030, quanto à proporção de municípios com presença de lixões e vazadouros. A partir dos valores sugeridos elaborou-se a Tabela 10 contendo a projeção do número de municípios com a presença de lixão. Dessa forma, somente a partir de 2030 o Brasil não teria mais municípios utilizando lixões para dispor seus resíduos.

\begin{tabular}{c|c|c} 
Ano & $\begin{array}{c}\text { \% de municípios } \\
\text { com lixões }\end{array}$ & $\begin{array}{c}\mathbf{N}^{\circ} \text { municípios } \\
\text { com lixões }\end{array}$ \\
\hline 2000 & 70 & 3.920 \\
\hline 2008 & 50 & 2.810 \\
\hline 2015 & 35 & 1.948 \\
\hline 2020 & 23 & 1.280 \\
\hline 2030 & 0 & 0 \\
\hline
\end{tabular}

Fonte: Elaborado a partir de MCidades (2011) e IBGE (2002)

Tabela 10- Simulação do número de lixões a serem erradicados até 2030

De acordo com levantamento da ABRELPE (2010), em 2010, o Brasil possuía 1.641 municípios com lixões. Isso significaria que em dois anos houve uma redução de 40\% na quantidade 
de municípios com lixões e em números absolutos 1.169 municípios deixaram de dispor seus resíduos em lixões. Porém, há limitações no estudo realizado pela ABRELPE devido sua metodologia ser amostral, o que resulta na extrapolação dos dados para o nível Brasil e regiões. Cabe dar destaque que para 2008, o relatório da ABRELPE (2008), identificou 1.657 municípios com a presença de lixões, diferindo em 1.153 municípios em relação ao dado da PNSB 2008. E, no relatório de 2007 a quantidade de municípios com presença de lixão é a mesma que em 2008, o que significaria que no intervalo de um ano não houve erradicação de nenhum lixão (Abrelpe, 2007). De toda forma, a informação dessa instituição pode indicar uma tendência na eliminação dos lixões, já que utilizando a metodologia amostral a redução de municípios com lixões foi de 1.657 para 1.641, ou seja, aproximadamente de $1 \%$.

\section{Custos da disposição final}

As informações referentes aos custos de disposição final são escassas nas pesquisas existentes no Brasil. Assim, utilizou-se a base de dados do SNIS para o levantamento dos custos da disposição final dos RSU. Diferentemente da Pesquisa Nacional de Saneamento Básico, o SNIS não trabalha com a totalidade dos municípios brasileiros, mas sim com amostras. A cada ano da série tenta-se aumentar o número de municí- pios participantes, mantendo-se os anteriores. É importante destacar que no SNIS nem todos os municípios respondem a todas as perguntas, sobretudo no que diz respeito às despesas. Sendo assim, o levantamento de custo da disposição final de resíduos foi elaborado a partir da média dos dados existentes referentes às publicações da série histórica do SNIS - Resíduos Sólidos entre aos anos de 2003 a 2008.

A Tabela 11 apresenta o valor contratual médio para disposição de resíduos e rejeitos em aterro sanitário. Para a elaboração dessa tabela foram excluídos os dados que extrapolavam a ordem de grandeza dos custos de disposição ${ }^{4}$. Observa-se que, apesar do aumento no número de informações obtidas sobre o custo de disposição em aterros sanitários, a amostra ainda é pouco representativa considerando o número total de municípios no Brasil.

Com exceção de 2007, em todos os outros anos o custo de disposição foi sempre mais elevado quando operado por empresa privada. Por um lado isso suscita a dúvida com relação à privatização do serviço; por que privatizar se o custo fica mais elevado? Por outro lado, há de se considerar que a operação do aterro por uma empresa privada pode ser mais rigorosa e atenta às exigências ambientais do que aqueles operados pela Prefeitura. Outra hipótese é de que as Prefeituras têm dificuldade para quantificar cla-

\begin{tabular}{|c|c|c|c|c|c|c|c|c|c|c|c|c|}
\hline & \multicolumn{2}{|c|}{2003} & \multicolumn{2}{|c|}{2004} & \multicolumn{2}{|c|}{2005} & \multicolumn{2}{|c|}{2006} & \multicolumn{2}{|c|}{2007} & \multicolumn{2}{|c|}{2008} \\
\hline & $\mathrm{R} \$ / \mathrm{t}$ & $\mathrm{n}$ & $\mathrm{R} \$ / \mathrm{t}$ & $\mathrm{n}$ & $\mathrm{R} \$ / \mathrm{t}$ & $\mathrm{n}$ & $\mathrm{R} \$ / \mathrm{t}$ & $\mathrm{n}$ & $\mathrm{R} \$ / \mathrm{t}$ & $\mathrm{n}$ & $\mathrm{R} \$ / \mathrm{t}$ & $\mathrm{n}$ \\
\hline Todas operadoras & 19,79 & 7 & 21,83 & 24 & 25,40 & 30 & 30,71 & 30 & 30,63 & 34 & 41,37 & 32 \\
\hline Empresa privada & 21,06 & 5 & 21,83 & 24 & 26,34 & 28 & 32,11 & 26 & 29,59 & 30 & 43,60 & 25 \\
\hline Prefeitura ou SLU & 16,63 & 2 & & & 8,47 & 1 & 23,04 & 3 & 42,27 & 1 & 20,02 & 3 \\
\hline Consórcio & & & & & 15,85 & 1 & 17,25 & 1 & 37,27 & 2 & 46,16 & 2 \\
\hline Outro & & & & & & & & & 37,01 & 1 & 39,60 & 2 \\
\hline
\end{tabular}

Nota: $n=$ tamanho da amostra | Fonte: Elaborado a partir de MCidades (2010)

Tabela 11- Valor contratual médio para disposição aterro sanitário

4- Como exemplo destas disparidades, cita-se o município de Londrina/PR que atribuiu o valor de $R \$ 15.205 .22,07$ por tonelada para disposição final dos seus resíduos em aterro controlado. 


\begin{tabular}{l|c|c|c|c|c} 
& 2004 & 2005 & 2006 & 2007 & 2008 \\
\hline Brasil & 21,83 & 25,40 & 30,71 & 30,63 & 40,37 \\
\hline Municípios pequenos & 38,63 & 36,08 & 61,22 & 54,08 & 54,25 \\
\hline Municípios médios & 19,24 & 23,7 & 29,48 & 28,12 & 35,46 \\
\hline Municípios grandes & 17,05 & 21,09 & 25,67 & 20,70 & 33,06 \\
\hline
\end{tabular}

Fonte: Elaborado a partir de MCidades (2010)

Tabela 12 - Valor contratual médio para disposição em aterro sanitário (R\$/t)

ramente os custos dos serviços quando são elas que o efetuam diretamente. Nesse sentido, não só essa diferença, mas também as grandes flutuações nos dados suscitam a desconfiança a cerca da qualidade desses dados. A resposta a estas questões extrapolam o escopo deste texto e devem ser levantadas por pesquisas específicas. Interessante notar o aparecimento, na amostra dos municípios, a adoção de consórcios públicos, a partir de 2005, na disposição final. A Tabela 12 resume o custo médio por tonelada para disposição de resíduos em aterros sanitários considerando o porte do município, no período de 2004 a 2008.

A partir da análise da Tabela 12 observa-se que há uma redução no custo por tonelada de resíduos aterrados quanto maior for a quantidade a ser aterrada, apontando o ganho de escala obtido nos municípios de maior porte e dando suporte à ideia dos consórcios públicos como mecanismo interessante para a disposição final de RSU.

\section{Conclusões}

A realização do diagnóstico dos RSU utilizando, principalmente, a Pesquisa Nacional de Saneamento Básico de 2000 e 2008 como base de dados permitiu identificar alguns pontos importantes a serem considerados na gestão e no gerenciamento dos RSU. Dessa forma, as recomendações foram divididas em dois grupos, o primeiro refere-se a destinação final dos RSU utilizando a compostagem como forma de tratamento dos resíduos orgânicos e, o segundo grupo trata da disposição final dos RSU, sobretudo no que diz respeito à erradicação dos lixões nos municípios brasileiros.

Com relação à compostagem recomenda-se a realização de estudos sobre as experiências bem sucedidas em âmbito nacional e internacional não somente no que diz respeito aos aspectos técnico-gerenciais (materiais, equipamentos, mão-de-obra, mercado existente, padrões de qualidade do composto etc), mas também envolvendo políticas públicas implantadas para incentivar o desenvolvimento dessa atividade. A partir dessas informações poder-se-á traçar programas mais realistas para a adoção da compostagem no país.

Ainda sobre a compostagem parece ser necessária a elaboração de norma técnica ou processo simplificado de licenciamento ambiental para pequenas unidades de compostagem, de forma semelhante ao que foi proposto para os aterros sanitários de pequeno porte, devido alguns municípios terem dificuldade de implantar unidades de compostagem para tratar pequenas quantidades de resíduo orgânico. Além disso, sugere-se que os programas de compostagem tenham como foco principal a coleta de resíduos orgânicos separados na fonte iniciando, por exemplo, nos grandes estabelecimentos (feiras livres, supermercados, restaurantes etc).

Outra questão que necessita de estratégias específicas diz respeito à erradicação dos lixões existentes e à implantação de novos aterros sanitários. Para atuar nesse campo, recomenda-se priorizar os esforços nos municípios de pequeno porte que, em 2008, correspondiam por $96 \%$ dos lixões existentes e, também nos municípios da região nordeste que, em 2008, eram responsáveis por $57 \%$ dos lixões existentes. Além disso, deve-se fortalecer, com aporte financeiro e apoio operacional, a formação de novos consórcios públicos para disposição final dos rejeitos. Concomitante, recomenda-se incentivar por meio de programas 
com financiamento e repasses da União, que os municípios com aterros controlados façam o seu encerramento e iniciem a implantação de aterros sanitários.

Por fim, a análise detalhada das informações relativas à gestão de RSU permitiu também identificar uma série de limitações e inconsistências nos dados existentes. Dentre elas destacam-se a não uniformidade nos universos das diferentes pesquisas, formulação de perguntas que permitem a duplicação das informações e baixa qualidade dos dados sobre custos da gestão dos resíduos sólidos. Nesse sentido, parece ser fundamental que o futuro Sistema Nacional de Informações sobre a Gestão dos Resíduos Sólidos (SINIR), previsto no Decreto $\mathrm{n}^{\circ} 7.404 / 2010$, venha superar tais limitações.

\section{Referências}

Abrelpe. (2007). Panorama dos resíduos sólidos no Brasil 2007. São Paulo: Associação Brasileira de Empresas de Limpeza Pública e Resíduos Especiais.

Abrelpe. (2008). Panorama dos resíduos sólidos no Brasil 2008. São Paulo: Associação Brasileira de Empresas de Limpeza Pública e Resíduos Especiais.

Abrelpe. (2010). Panorama dos resíduos sólidos no Brasil 2010. São Paulo: Associação Brasileira de Empresas de Limpeza Pública e Resíduos Especiais.

Ali, M. (2004). Sustainable composting: cases studies and guidelines for developing countries. Leicestershire: Water, Engineering and Development Centre, Loughborough University.

Araújo, E.L (2005). Estudo do uso dos recursos diretos e indiretos na coleta de resíduos sólidos urbanos. Dissertação (Mestrado). Programa de Pós-Graduação em Engenharia de Produção, Universidade Paulista. São Paulo.

Barreira, L.P (2005). Avaliação das usinas de compostagem do estado de São Paulo em função da qualidade dos compostos e processos de produção. Tese. (Doutorado). Programa de Pós Graduação em Saúde Pública, Universidade de São Paulo. São Paulo.

Brasil. (2010). Decreto 7.404/2010. Regu- lamenta a Lei no 12.305, de 2 de agosto de 2010, que institui a Política Nacional de Resíduos Sólidos, cria o Comitê Interministerial da Política Nacional de Resíduos Sólidos e o Comitê Orientador para a Implantação dos Sistemas de Logística Reversa, e dá outras providências.

Brasil. (2010). Lei 12.305/2010 Institui a Política Nacional de Resíduos Sólidos; altera a Lei no 9.605, de 12 de fevereiro de 1998; e dá outras providências.

IBGE. (2002). Pesquisa Nacional de Saneamento Básico 2000/Banco Multidimensional de Estatísticas. Recuperado junho 1, 2011, de http://www.bme.ibge.gov.br

IBGE. (2010). Pesquisa Nacional de Saneamento Básico 2008/Banco Multidimensional de Estatísticas. Recuperado junho 1, 2011, de http://www.bme.ibge.gov.br

IPEA. (2012). Diagnóstico dos Resíduos Sólidos Urbanos. Relatório de Pesquisa. Disponível em http://www.ipea.gov.br/agencia/images/ stories/PDFs/relatoriopesquisa/121009_relatorio_residuos_solidos_urbanos.pdf.

Massukado, L. M. (2008). Desenvolvimento do processo de compostagem em unidade descentralizada e proposta de software livre para o gerenciamento municipal dos resíduos sólidos domiciliares (Ph.D.). Universidade de São Paulo, São Carlos.

MCidades. (2010). SNIS Série Histórica 9. Brasília: Secretaria Nacional de Informações sobre Saneamento, Ministério das Cidades.

MCidades. (2011). Plano Nacional de Saneamento Básico - Plansab. Brasília: Ministério das Cidades.

MMA. (2010). Manual para implantação de compostagem e de coleta seletiva no âmbito de consórcios públicos. Brasília: Ministério do Meio Ambiente.

Secretaria de meio ambiente (2004). Goldemberg aceita proposta de desativação da Usina de Vila Leopoldina em setembro. Disponível em

http://www.ambiente.sp.gov.br/destaque/

2004/maio/19_usina_leopoldina.htm. Acesso em 30 jun 2011. 